\title{
Students' Views on Self - Directed Learning Approach: Exploring the Challenges and Implications to Teaching and Learning
}

\author{
Faye Joy F. Delos Reyes ${ }^{1}$, Dennis G. Caballes ${ }^{2}$ \\ a delosreyes1902690@ceu.edu.ph,dennis.caballes@benilde.edu.ph \\ Commonwealth High School, Manila 1420, Philippines \\ De La Salle-College of Saint Benilde, Manila 1420, Philippines
}

\begin{abstract}
We have been experiencing a lot of challenges in education particularly on teaching and learning but several plausible remedies are made available to us, teachers. Since they are not prepared for the challenging and isolated learning environment, many students who take online courses experience dissatisfaction and disappointment. Self-directed learning (SDL), a conventional learning philosophy, is a foundation that can help students develop features of a customized system that lets them control their overall learning experiences and track their own success. The objective of this study is to investigate the effectiveness of SDL in an online environment using the following specific domains: the teaching environment, learning environment and the technology. These three domains would like to focus on how a learner could handle SDL to make it effective. The research was carried out using researcher - made questionnaire distributed to 65 learners.
\end{abstract}

Keywords: self - directed learning; teacher environment; learner environment; technology

\section{Main text}

In this present time, a flourishing change in education was evident amidst the pandemic. With all the changes that is required, everyone was obliged to adapt to it. One of the solutions presented by the Department of Education (DepEd) was conferred in DepEd Order No. 12 series 2020 [1] which streamlines on the adoption of Most Essential Learning Competencies (MELCs) and prohibition of face - to - face classes. The MELCs' release is part of the Department's long-term response, especially during emergencies, as well as a response to the current pandemic's challenges; hence, it can be used as a tool to ensure curriculum consistency under some situations. As we foresee difficulties in learning delivery, the MELCs will enable to concentrate instruction on the most important and indispensable competencies that our learners must acquire. It will also make the process of adapting to classroom-based learning tools for distance learning easier. Moreover, it also indicated the use of different modalities and materials to be used in the current situation. With face-to-face classes still prohibited due to the public health situation, the incorporation of SLMs with alternative learning delivery modalities (modular, television-based, radio-based teaching, mixed, and online) will ensure that all learners will still have access to quality basic education for SY 2020-2021. The self - learning modules (SLMs) was created by the experts to be used by the learners in addition with the radios, televised lessons and online classes. 
The Higher Educational Institutions (HEI's) response for continuing education, however, was the implementation of flexible learning. There is a pressing need to investigate other creative learning modalities that will make the transition from conventional to flexible teaching and learning choices easier. Since learners vary in terms of time, speed, and place, these options allow for the customization of delivery modes to meet students' needs for quality education [2]. Learners' particular needs in terms of location, speed, process, and products of learning are discussed in the design and delivery of programs, courses, and learning interventions. It encompasses the use of both digital and non-digital technologies, as well as face-to-face or in-person instruction, out-of-classroom learning, or a mixture of the different modes of delivery. It ensures the continuation of inclusive and open education when conventional teaching methods are unavailable, such as in the event of national emergencies.

Self - Directed Learning (SDL) is characterized as a process in which individuals diagnose their own learning needs, develop learning goals, identify human and material resources for learning, select and implement effective learning strategies, and evaluate learning outcomes, with or without the assistance of others. [3]. In the fields of learning and education, the concept of self-directed learning has become apparent. It proposes that with more help and inspiration, people will become more self-directed, alleviating the issue of spoon feeding. Simultaneously, a learning environment such as self-directed learning seems to be capable of improving one's life. This mode of learning will encourage the students to study better and do their best. It will also develop their decision - making skills as early as young adolescence that could prepare them in the future.

Several models of SDL approach were developed and one of which, the Personal Responsibility Orientation model is an updated model that is more suitable in the present era. The Personal Responsibility Orientation model of Self-Direction in Learning emphasizes self-directed learning in relation to the distinction between the teaching-learning process and a learner's personal characteristics. The Person Process Context model (Figure 1) is a revised and reconfigured Personal Responsibility Orientation model that includes individual characteristics, a process encompassing the teaching-learning transaction, and a context that considers the environmental and sociopolitical atmosphere, such as organizational policies and political milieu. While previous models placed the individual at the core of self-directed learning, the Person Process Context model recognizes that the best situation for self-directed learning occurs when the person, process, and context are all in harmony [4]. All these elements should be identified, planned by the learner to perfectly execute each step for SDL.

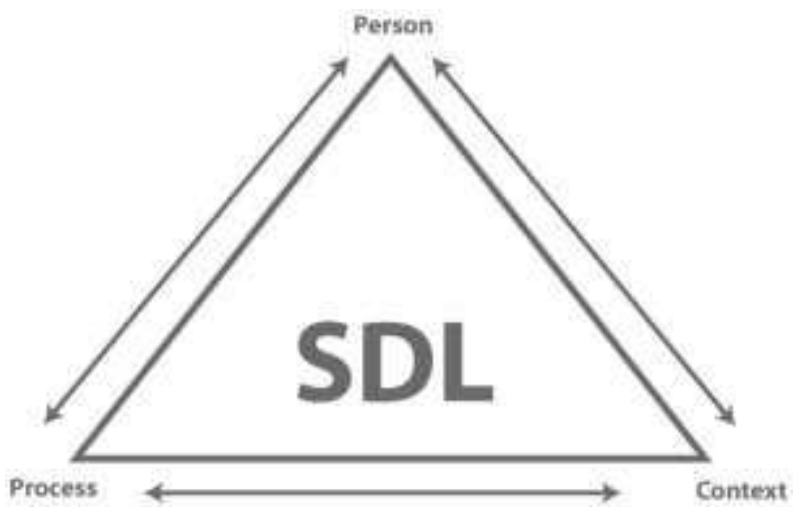

Figure 1.

Person, Process Context Model

Hiemstra and Brockett (2019) 
SDL's main tenet is that students are responsible for their own learning beyond what is provided by an external entity (eg, faculty member, the curriculum). In the new system, a teacher can provide learning goals, tests, and tools to help students learn the content in a more conventional educational environment. With SDL, on the other hand, the learner can take the lead by setting learning objectives, identifying tests that provide guidance, and identifying tools to assist them in achieving their objectives. By taking charge of their own education, students assume responsibility for certain tasks that were previously dictated by the teacher, who is now free to promote learning [5]. Individuals must take action and responsibility for their own education. Learners have complete autonomy in setting goals and determining what is worthwhile to learn, both within and outside of formal educational institutions. When teachers are active, they should act as facilitators rather than transmitters of information.

The implementation of SDL requires planning and thorough study. Before implementing SDL, it is recommended that facilitators be conscious of those abilities in which students need special instruction on. Students should also keep track of their own learning growth, recognize places where they are falling short, and work on these strengths to better themselves. Facilitators and students working together can be beneficial to the students as they become independent and lifelong learners. Specific directions and well-organized learning materials for working independently that will enable students to complete their own self-designed assignments and will increase students' control of the learning process, were among the methods used to improve self-directed learning. Students may benefit from reflection and input on their learning processes, as well as reflection on their learning [6]. This will expand their understanding on how to prosper their skills to perform tasks correctly. In line with this, learner's attitude towards self - directed learning is essential to make it effective. Learners are obliged to adopt with these changes and encouraged to learn on their own.

In the Philippine education system, DepEd designed a lot of modalities that which would be accepted by the students. In the remote areas, radio - based mode of teaching was implemented due to some technical problems about the internet connection. However, in the city, where the connection can be strong and stable, online or virtual classes were regulated using the SLMs. These modalities can satisfactorily achieve the goals of SDL.

\subsection{Research Questions}

This study primarily aims to assess the learner's view on self - directed learning approach. Specifically, it sought to answer the following questions:

1. What are your views and opinions regarding the implementation of self - directed learning approach?

2. Are the students' needs attained in the implementation of SDL in terms of:

2.1 Instruction

2.2 Learning

2.3 Technology 


\subsection{Materials and Methods}

This study utilized the descriptive method of research. It surveyed the views of the learners about SDL implementation and evaluated if their objectives were attained. The respondents of the study supposedly consist of 100 learners in Grade 9 for Academic Year 2020 - 2021. However, only 65 respondents positively participated on the study. The criterion on the selection of the respondents depends on the teaching load given. To be able to ensure that the respondents have a concrete definition of self - directed learning, the researcher conducted an orientation about SDL and steps on how to proceed with the specific type of learning. The researcher also mentioned the steps on how the respondents would plan. The Person, Process and Context Model (Figure 1) was explained and elaborated. To deduce the model, the researcher implied six steps to be followed: 1. Goal Setting (Development of learning objectives); 2. Assessment (Measurement that the learner is progressing and accomplished the goal); 3. Activities (Defining the structure and sequence of activities); 4. Timeline (Benchmarking when activities will be accomplished); 5. Resources (Identifying the resources needed to accomplish the goal) and 6. Feedback (Identifying individuals who may provide feedback on the learning). An assigned topic for Quarter 3, specifically Volcanoes was used in the study to be part of its scope and limitation.

The researcher modified a questionnaire for this study. The first questionnaire is composed of two parts. The first part was a narrative question where the respondents can indicate their comments and suggestions on their definition of SDL. The second part was an adopted diagnostic tool from SIM University (UniSIM) wherein items were chosen based on factor analysis. It measures the effectiveness of SDL approach to the learners. It can act as a self-diagnosis tool for students to better grasp their own learning requirements. These items were assessed on a scale of 1 (Strongly Disagree) up to 5 (Strongly Agree). The questionnaire underwent a reliability testing before it was distributed to the respondents. The respondents included in the reliability testing were not involved in the study. Table 1 showed the computed Cronbach's alphas for the 11 - item assessment on the views of the learners on the implementation of SDL approach which was 0.749. After establishing the internal consistency of the items, the questionnaire was distributed to the respondents.

Table 1. Reliability Test Results

\begin{tabular}{ll}
\hline Cronbach's Alpha Value & No. of Items \\
\hline 0.749 & 11 \\
\hline
\end{tabular}

The quantitative data that were collected was analyzed using SPSS ver. 23 statistical software. Frequency and percentage regarding the implementation of SDL approach to test the views and opinions of the implementation of SDL approach standard deviation and central tendency were used. T - test was applied to resolve the implementation of SDL. 


\subsection{Scoring of Responses}

The following scale was used to evaluate the views of the learners on the implementation of SDL approach in response to the new normal.

Table 2. Responses Scoring

\begin{tabular}{llll}
\hline Options & Scale & Adjectival Rating & Interpretation Rating \\
\hline 5 & $4.1-5.00$ & Strongly Agree & Very Positive \\
4 & $3.4-4.00$ & Moderately Agree & Positive Agree \\
3 & $2.5-3.49$ & Neutral & Neutral \\
2 & $1.5-2.49$ & Moderately Disagree & Negative Disagree \\
1 & $1.0-1.49$ & Strongly Disagree & Very Negative \\
\hline
\end{tabular}

The items in the questionnaire were all positively stated. Statistical treatment of data included comparing the mean values by creating rankings

\section{Results and Discussion}

\subsection{Views and Opinions for the Implementation of SDL}

Descriptive analyses regarding the views and implementation of SDL based on the experiences of the learners were included in the topic. Table 2 shows the result of the respondents' perspective of SDL. Most of the respondents believe that "This will help me expanding my knowledge of my own abilities" (83.09\%); "It was based on my own decision" (12.30\%) and "This will serve as my own training in the future" (4.61\%). These results could infer that learners believed that SDL will enable them to evaluate their own strengths and weaknesses. A self-directed learner is self-disciplined, curious, and capable of using basic research skills and time management. Self-directed learners may also create a strategy for completing work, enjoying learning, and having a goal-oriented mindset [7]. Considering their assessment of their own capabilities, this idea will let the learners address their attitudes and skills.

Self-directed learning is a mechanism in which people diagnose their own learning needs, formulate learning objectives, determine human and material resources for learning, choose and execute effective learning strategies, and evaluate learning outcomes on their own, with or without the assistance of others. Self-directed learning is explained as when students who can recognize their own learning needs are driven by internal factors (such as their own learning needs and interests), and actively participate in lecturer-student interaction [8]. As a result, self-direction in learning encompasses both external and internal influences that predispose an adult to take responsibility for learning-related thoughts and behavior. Self-directed learning and learner selfdirection are inextricably linked. Internal and external dimensions of self-direction can be interpreted as a continuum, with ideal learning conditions occurring when a learner's level of self-direction is matched with the degree to which self-directed learning opportunities are available. A self-directed learner is self-motivated and persistent in their studies, takes responsibility for their own education, and sees issues as opportunities rather than obstacles. The respondents enact that SDL will hold them responsible for their learning. 
Table 3. Frequency and Distribution of the Views and Opinions on the Implementation of SDL

\begin{tabular}{lll}
\hline & Frequency & Percentage \\
\hline It was based on my own decision & 8 & $12.30 \%$ \\
This will help me expanding my knowledge of my own abilities & 54 & $83.09 \%$ \\
This will serve as my own training in the future & 3 & $4.61 \%$ \\
\hline
\end{tabular}

\subsection{Attainment of the Implementation of SDL}

\subsubsection{Instruction}

Table 3 shows the difference on the attainment of the SDL implementation in terms of instruction. Three items from the diagnostic test were selected to assess instruction specifically items 1, 2 and 8. Item 1 "I am able to present the information in my assignments clearly"; Item 2 "I do not understand what my instructor says during online presentations"; and Item 8 "I cannot relate the content of the readings to the course objectives." The computed mean for Item 1 of 4.0615 with an adjectival rating of positively agree; Item 2 of 2.830 and Item 3 of 2.7692 that has both adjectival rating of neutral; and a computed T - value of 1.3548. This means that the null hypothesis is accepted. Therefore, there is no significant difference on each factor that aims to assess different abilities namely assignment management, online learning proficiency and comprehension competence which will be used for the attainment of the implementation of SDL in terms of instruction.

Studies state that instructors must be equipped with the skills necessary to promote self-directed learning in their classrooms. Establishing an optimum self-directed learning atmosphere while maintaining an efficient instructional process was a challenge for most instructors. Adults learn better when they are guided by an individualized process that allows them to take more responsibility for their own learning [9]. Learners should be given clear instructions as well to come up with an output which is aligned with the topic or discussion as they present their ideas in class. It is critical to maintain communication among students at various locations, the teacher, and the support staff. To maintain adequate collaboration, an effective relationship between students and technology is needed. It's also necessary to provide activities that encourage students to engage with one another. Finally, instructors must foster cooperation among students at different locations in order to increase participation. Even though online learning was used in most schools nowadays, other ways are still available to make teaching - learning process effective.

Learning materials play an important role in all learning models. A strategic implementation of learning materials, including content and background coordination, to meet the need for Self-Directed Learning [10]. Major instructional support materials are critical to the success of education initiatives. Published manuals, textbooks, videotapes, Internet tools, and the use of alternative means of communication such as telephone, mail, and classroom activities to supplement online interactions are all examples of educational support. Learning materials, for example, must be planned and written in such a way that users can research independently. There are instructional design elements including learning goals, as well as research plans, questions, and examples to consider. Simultaneously, the instructional materials must be straightforward and accurate in their teaching. Finally, self-evaluation review must be available for corrections and changes. An appropriate instructional material that fits their age and comprehension would suffice the needs of the learner to execute SDL in alignment with the lesson objectives. In the current setting of DepEd, modules were distributed to the learners who were unable to attend online classes. 
Table 4. Attainment of SDL Implementation in Terms of Instruction

\begin{tabular}{|c|c|c|c|c|c|}
\hline & Mean & $\begin{array}{l}\text { Standard } \\
\text { Deviation }\end{array}$ & $\mathrm{T}-$ Value & Interpretation & Decision \\
\hline $\begin{array}{l}\text { I am able to present the information in my assignments } \\
\text { clearly }\end{array}$ & 4.0615 & 0.70438 & \multirow{3}{*}{1.3548} & \multirow{3}{*}{$\begin{array}{l}\text { Not } \\
\text { Significant }\end{array}$} & \multirow{3}{*}{$\begin{array}{l}\text { Accept } \\
\text { Ho }\end{array}$} \\
\hline $\begin{array}{l}\text { I do not understand what my instructor says during online } \\
\text { presentations }\end{array}$ & 2.8308 & 1.20635 & & & \\
\hline $\begin{array}{l}\text { I cannot relate the content of the readings to the course } \\
\text { objectives }\end{array}$ & 2.7692 & 1.08641 & & & \\
\hline
\end{tabular}

\subsubsection{Learning}

Table 4 shows the difference on the attainment of the SDL implementation in terms of learning. Five factors from the diagnostic test were selected to assess attainment of learning, specifically items 3,5,7, 9 and 10 . These are Item 3 "I am demoralized when I do not meet the expectations set for myself in my studies"; Item 5 "I prefer to do other things than study the learning materials or resources"; Item 7 "I learn from my instructor and peers during seminars", Item 9 "I feel confident when taking tests and examination" and Item 10 "I set targets to achieve for assignments and examination for each course". A computed mean for Item 3 was 3.4923, Item 7 with 3.7321, Item 9 with 3.8769 and Item 10 with 3.7538; all of the mentioned items have an adjectival rating of positively agree. However, Item 5 has a mean of 3.0462 with an adjectival rating of moderately disagree. The computed $\mathrm{T}-$ value was 0.4235 . This means that the null hypothesis is rejected. Therefore, there is a significant difference on each factor that focuses on different abilities particularly stress management, procrastination management, seminar learning proficiency, comprehension competence and time - management which were used for the attainment of the implementation of SDL.

As a self-directed learner, one must have the utmost control over one's learning time, speed, and place. However, when all factors are considered, it is clear that self-directed learning is not solely about mastering learning techniques. Self-directed learning includes more than just controlling the learning environment. The capacity and willingness to reflect, rational judgment, and the requisite knowledge of alternatives are also important [11]. Learners' willingness and motivation should always be present to achieve the aim of SDL. However, due to advanced technology, distractions on learning were always displayed. Procrastination is one factor that affects learning motivation. Scholars also found that procrastination is simpler in an online learning environment than in a conventional face-to-face classroom, owing it to the lack of a strict timetable in online classes. In an online environment, learners can wait until the last minute to do course-related reading. As a result, online learners need improved motivational techniques to prevent learning procrastination [12].

It is recommended that facilitators be conscious of those abilities in which students need special instruction before implementing SDL. Students should also keep track of their own learning growth, recognize places where they are falling short, and work these strengths to better themselves. Facilitators and students working together can be beneficial in helping students become independent and lifelong learners [13]. Collaborative learning could be used to impart learning to the learners. Both teachers and students are willing partners of the learning process in collaborative learning. Information isn't passed down to students; rather, it comes from active discussion among those who want to better understand and apply concepts and techniques [14]. It is a method of teaching and learning that is instructional. It entails groups of students cooperating to solve a problem, complete a task, or produce a product. Learners may build their own specific conceptual framework in a collaborative learning environment rather than relying solely on the framework of an expert or a 
document. Experts have opportunities for interaction with peers.

Another challenge students face was poor time management due to the large number of assignments. Assignment scheduling that is reasonable and versatile has a positive impact on online students' learning. Students who have good learning habits and a strong desire to learn and who stick to their assignments are more likely to succeed in online courses [15]. Learners should learn to prioritize and organize their personal duties from their studies. They should set targets to be accomplished for the day or week to be able to finish all of their task. Time management is dependent on how well each understand their desires and whether they have the necessary willpower to carry them out in acceptable activities, resolve procrastination, maintain selfcontrol and handle criticism. Time management also provides the ability to solve spatial issues (keeping items in order, etc.) and physical environment organization [16].

Table 5. Attainment of SDL Implementation in Terms of Learning

\begin{tabular}{|c|c|c|c|c|c|}
\hline & Mean & $\begin{array}{l}\text { Standard } \\
\text { Deviation }\end{array}$ & $\mathrm{T}-$ Value & Interpretation & Decision \\
\hline $\begin{array}{l}\text { I am demoralized when I do not meet the expectations set } \\
\text { for myself in my studies }\end{array}$ & 3.4923 & 1.13362 & \multirow{5}{*}{0.4235} & \multirow{5}{*}{ Significant } & \multirow{5}{*}{$\begin{array}{l}\text { Reject } \\
\text { Ho }\end{array}$} \\
\hline $\begin{array}{l}\text { I prefer to do other things than study the learning materials } \\
\text { or resources }\end{array}$ & 3.0462 & 1.30421 & & & \\
\hline I learn from my instructor and peers during seminar & 3.7321 & 1.17567 & & & \\
\hline I feel confident when taking tests and examination & 3.8769 & 0.99228 & & & \\
\hline $\begin{array}{l}\text { I set targets to achieve for assignments and examination for } \\
\text { each course }\end{array}$ & 3.7538 & 1.18626 & & & \\
\hline
\end{tabular}

\subsubsection{Technology}

Table 5 presents the difference on the attainment of the SDL implementation in terms of instruction. Two items from the diagnostic test were selected to assess technology, specifically items 4 and 6 . These are Item 4 "I have problems using computer software and hardware" and Item 6 "I do not know how to prepare for online discussions." The computed mean for Item 4 has 3.0615, while Item 6 has 2.7597 that has both adjectival rating of neutral. A computed $\mathrm{T}$ - value of 0.7815 which could imply that the null hypothesis is accepted. Therefore, there is no significant difference on each factor that aims to assess different abilities, namely technical proficiency and online discussion proficiency which will be used for the attainment of the implementation of SDL in terms of technology.

New advances in 21st-century education, such as online learning opportunities, pedagogical shifts, and Internet access on mobile devices, have increased learners' aspirations to take more responsibility for their own learning [17]. Since internet facilities can improve learning, technology plays an important role on whether a course succeeds or fails. The ability to improve self-directed learning by pointing to tools and support materials that can be accessed and integrated directly into a lesson for "real time" learning with direct application to the lesson in progress is the most exciting aspect of using the Web, social media, and internet facilities as a distribution tool. Students who are more willing to follow a web-based learning approach have a greater understanding of online and offline course design and are more mindful of the importance of teaching presence in course and facilitation design. 
Table 6. Attainment of SDL Implementation in Terms of Technology

\begin{tabular}{lllll}
\hline & Mean & $\begin{array}{l}\text { Standard } \\
\text { Deviation }\end{array}$ & T - Value & Interpretation \\
\hline I have problems using computer software and hardware & 3.0615 & 1.32142 & 0.7815 & $\begin{array}{l}\text { Not } \\
\text { Significant }\end{array}$ \\
I do not know how to prepare for online discussions & 2.7597 & 1.28658 & Accept & Ho \\
\hline
\end{tabular}

\section{Conclusion}

Findings from this study has led to the conclusion on determining the strategies on implementation of SDL.

Self - directed learning could be one method of delivery system for the learners. However, proper implementation and execution should be done for its success which includes the teacher, learner and resources. In order for students to be self-directed, positive instructor standards are critical. Students would be competent to monitor and master SDL in the learning environment and in their own learning if positive/constructive instructor standards are present. Students were able to keep track of their learning experiences, master the material before coming to class, and create online interactions with their peers and instructors. In terms of the learning process, it also called for self-evaluation, peer evaluation, and teacher evaluation.

If the learning environment allows for self-directed learning, the quality of teaching and learning can increase. For a useful and long-term use, sustainable interventions, preparation, monitoring, and execution of the learning environment must be carefully considered and strategized platform where teachers could develop their skills and competencies are needed in their professional development.

Active participation on initiatives from the supervisors and the teachers could engage both on an action research process where problems could be solved by sharing common, constructive and valuable ideas to ensure better teaching - learning process. Since a well-designed, self-directed learning environment allows for more versatility in learning and increases students' capacity to become more self-directed, this is the case. Over all, it will benefit learners' future learning experiences and help them live a better life.

\section{References}

DepEd Order No. 12 Series 2020 "Adoption of the Basic Education Learning Continuity Plan for School Year 2020 - 2021 in light of the Covid - 19 Public Health Emergency". Department of Education. https://www.deped.gov.ph/wpcontent/uploads/2020/06/DO_s2020_012.pdf

CMO No. 4 Series 2020 "Guidelines on the Implementation of Flexible Learning". Commission on Higher Education. https://ched.gov.ph/wp-content/uploads/CMO-No.-4-s.-2020-Guidelines-on-theImplementation-of-Flexible-Learning.pdf

Dr. Emad Shahrouri. 2016. “The Impact Of Garrison's Model Of Self-Directed Learning On Improving Academic Self- Concept For Undergraduate Students" "Aue As A Model” International Journal of Education, Learning and Development Vol.4, No.10, pp.36-45, December 2016 
Curran, V., Gustafson, D., Lannon, H, Wang, C. \& Garmsiri, M. “Adult Learners Perception of Self Directed Learning and Digital Technology usage in Continuing Professional Education: An Update for the Digital Age". Journal of Adult and Continuing Education 2019, Vol. 25(1) 74-93

Robinson, J. \& Persky, A. "Developing Self - Directed Learners". American Journal of Pharmaceutical Education 2020; 84 (3) Article 847512

Voskamp, A., Kuiper, E. \& Volman, M. “Teaching Practices For Self-Directed And Self-Regulated Learning: Case Studies In Dutch Innovative Secondary Schools", Educational Studies, DOI: $10.1080 / 03055698.2020 .1814699$

De Beer, J. \& Gravett, S., 2016, 'The affordances of case-based teaching for self-directed learning: A case study with first year student-teachers', in E. Mentz \& I. Oosthuizen (eds.), Self-directed learning research, pp. 35-71, AOSIS, Cape Town. http://dx.doi.org/10.4102/aosis.2016.sdlr14.02

Du Toit, A. \& Pool, J., 2016, 'Pre-service teacher students' expectations of self-directed learning in an undergraduate blended-learning course', in E. Mentz \& I. Oosthuizen (eds.), Self-directed learning research, pp. 213-238, AOSIS, Cape Town. http://dx.doi.org/10.4102/aosis.2016.sdlr14.08

Shireen, H., Haliza ,H. J., \& Khairil, I. O. (2000). Teaching via the web international seminar on education and training in an IT environment. ISET 2000 at UNITAR, Petaling Jaya, Malaysia

Brand - Gruwel, S., Van Merriënboer, J. J., Könings, K. D., Seidel, T., (2014). Differences between students' and teachers' perceptions of education: Profiles to describe congruence and friction. Instructional Science, 42(1), 11-30.

Loeng, Svein. 2019. "Self-Directed Learning: A Core Concept in Adult Education" Hindawi Education Research International Volume 2020, Article ID 3816132, 12 pages https://doi.org/10.1155/2020/3816132

Song, L. \& Hill. J. 2016. “A Conceptual Model for Understanding Self-Directed Learning in Online Environments" Journal of Interactive Online Learning www.ncolr.org/jiol, Volume 6, Number 1, Spring 2007 ISSN: 1541-4914

Bhandari, B., Chopra, D. \& Singh, K., 2020. “Self - Directed Learning: Assessment of students' Abilities and their Perspective". Adv Physiol Educ 44: 383-386, 2020; doi:10.1152/advan.00010.2020

Trentin, G. (2010). Networked collaborative learning: Social interaction and active learning. Elsevier.

Kohan N, Soltani Arabshahi K, Mojtahedzadeh R, Abbaszadeh A, Rakhshani T, Emami AH. Self- Directed Learning Barriers In A Virtual Environment: A Qualitative Study. J Adv Med Educ Prof. 2017;5(3):116-123

Briede, Baiba. 2016. Purposefulness and Time Management Components of Self-directed Studies at Latvia. Rural Environment. Education. Personality. ISSN 2255- 808X Jelgava, 13.-14.05.2016.

Jaleel, S. \& Anuroofa, O.M. 2017. A Study on the Relationship between Self Directed Learning and Achievement in Information Technology of Students at Secondary Level. Universal Journal of Educational Research 5(10): 1849-1852, 2017 http://www.hrpub.org DOI: 10.13189/ujer.2017.051024 